\title{
Brain Metabolites and Cognitive Function among Older Depressed and Healthy Individuals Using 2D MR Spectroscopy
}

\author{
Virginia Elderkin-Thompson*,', M Albert Thomas², Nader Binesh², Jim Mintz ${ }^{3}$, Ebrahim Haroon', \\ Jennifer J Dunkin' and Anand Kumar' \\ 'UCLA Neuropsychiatric Research Institute and Hospital, USA; ${ }^{2}$ UCLA Department of Radiology, USA; ${ }^{3}$ UCLA Neuropsychiatric Research \\ Institute Biostat Core, USA
}

\begin{abstract}
Brain metabolites of choline $(\mathrm{Ch})$ and myo-Inisotol $(\mathrm{ml})$ have been reported as elevated among geriatric depressed patients. Twodimensional (2D) magnetic resonance spectroscopy (MRS) provides estimates of $\mathrm{Ch}, \mathrm{ml}$, and creatine ( $\mathrm{Cr}$ ) similar to one-dimensional MRS, and it also estimates the resonances of the Ch-containing compounds of phosphoethanolamine (Pe) and phosphocholine (PCh). In this cross-sectional geriatric study, 14 depressed patients and 14 healthy volunteers who were comparable in age, gender, education, comorbid medical burden, and Mini-Mental State Examination (MMSE) scores completed 2D MRS and a neurocognitive battery. A voxel in the left dorsolateral cortex, which was comprised of approximately $60 \%$ white matter, was used to estimate the CR ratios of Ch, PCh, $\mathrm{Pe}$, and $\mathrm{ml}$. Composite scores for cognitive function were developed for verbal learning, recall, recognition, executive function, hypothesis generation, and processing speed. Among nondepressed subjects, cognition was positively correlated with $\mathrm{Ch} / \mathrm{Cr}$ and $\mathrm{ml} / \mathrm{Cr}$ and negatively correlated with PCh/Cr in four domains of verbal learning, recognition, recall, and hypothesis generation. In contrast, depressed patients did not have consistent relationships between $\mathrm{Ch} / \mathrm{Cr}, \mathrm{ml} / \mathrm{Cr}$, and $\mathrm{PCh} / \mathrm{Cr}$ and cognition. There was a significant difference in the overall pattern of associations between the four metabolites and verbal learning and processing speed in depressed patients compared to healthy controls. The attenuated relationship between metabolites and specific cognitive domains in patients with late-life MDD suggests that the level of cognitive performance observed during depressive episodes may be associated with changes in biochemistry within the frontostriatal neuronal circuitry.
\end{abstract}

Neuropsychopharmacology (2004) 29, 225 I-2257, advance online publication, 8 September 2004; doi: I 0. I 038/sj.npp. I 300553

Keywords: neuroimaging; cognition; spectroscopy; depression; elderly; metabolites

\section{INTRODUCTION}

Neuronal circuits regulate and modulate emotional and cognitive functions in humans, primates, and less evolved animals (Fuster 2000, 2001; Goldman-Rakic 1995; Mesulam 2000). These circuits form the communicating pathways between the prefrontal cortex and the primary and associative processing regions of the brain (Fuster 2000, 2001; Price 2001), and impairment of these circuits are believed to contribute to mood and psychiatric disorders (Drevets and Raichle, 1992; Kumar and Cook, 2002; Thomas et al, 2002).

Magnetic resonance spectroscopy (MRS) is a neuroimaging technique that makes possible the examination of the biochemical correlates of mood, cognition, and related behavioral domains. Among elderly patients, there is

\footnotetext{
*Correspondence: Dr V Elderkin-Thompson, UCLA Neuropsychiatric Research Institute and Hospital, 760 Westwood Plaza, Rm C8-688, Los Angeles, CA 90024-1759, USA, Tel: + I 310794 6398, Fax: + I 310 206 4996, E-mail: velderkin@mednet.ucla.edu

Received 20 November 2003; revised 8 July 2004; accepted 13 July 2004
}

growing evidence from one-dimensional (1D) MRS that the level of choline $(\mathrm{Ch})$ is elevated during unipolar depression in the frontal cortex and basal ganglia (Charles et al, 1994; Hamakawa et al, 1998; Kumar et al, 2002; Steingard et al, 2000), and that it decreases with successful treatment (Renshaw et al, 1997). The $\mathrm{Ch}$ resonance also includes the compounds of glycerophosphocholine, phosphoethanolamine $(\mathrm{Pe})$, and phosphocholine (PCh) (Miller, 1991), and it is not clear which of the Ch compounds becomes elevated with the onset of depression.

myo-Inisotol (mI) has also been reported as elevated in the frontal cortex among elderly depressed patients using 1D MRS (Kumar et al, 2002). It is involved in several important cellular processes in the brain as a marker of phospholipid turnover and gliosis, a secondary messenger and a detoxifying molecule (Catani et al, 2002; LopezVillegas et al, 1997; Shonk et al, 1995). In addition to depression, $\mathrm{mI}$ has been observed as elevated in patients with Alzheimer's disease, mild cognitive impairment (Huang et al, 1999; Kantarci et al, 2000; Kumar et al, 2002), primary progressive aphasia (Catani et al, 2003), and hypertension (Catani et al, 2002). 
The goal of this study was to examine the relationships between cognition and the biochemical concentrations of $\mathrm{mI}$ and $\mathrm{Ch}$ across healthy and depressed geriatric volunteers. Two-dimensional (2D) MR spectroscopy is a new technique that, by virtue of a second spectral dimension, can differentiate the $\mathrm{Pe}$ and $\mathrm{PCh}$ resonances from the $\mathrm{Ch}$ resonance. Hence, in addition to $\mathrm{Ch}$, we could examine how $\mathrm{PCh}$ and $\mathrm{Pe}$ are associated with cognitive performance and if the associations of the three metabolites are different across diagnostic groups. The $\mathrm{mI}$ resonance was examined to determine if its relationship to cognition also varied across groups and if it had a recognizable pattern vis-à-vis the Ch compounds. NAA was not a research focus due to the lack of support in the literature for an association between NAA levels and late-life depression (Kumar et al, 2002; Charles et al, 1994).

\section{METHODS}

\section{Subjects}

This study was conducted with approval from the Institutional Review Board at the University of California, Los Angeles, in accord with the Helsinki Declaration of 1975. In all, 28 community-dwelling volunteers, 14 depressed and 14 healthy, were recruited from surrounding communities with newspaper and radio announcements. The exclusion criteria included history of substance abuse per the Structured Clinical Interview for Diagnosis for Axis I disorders (SCID); clinical evidence of dementia; presence of neurological or endocrine disease such as diabetes, Parkinson's disease, or syphilis; history of head trauma; presence of a current unstable or serious medical illness; or presence of contraindicators for neuroimaging such as an implanted electronic device or skeletal prosthesis. Depressed patients met DSM-IV criteria for major depression, scored $\geqslant 15$ on the 17-item Hamilton Rating Scale for Depression (Hamilton, 1960), and were drug free for antipsychotics, anxiolytics, and antidepressant medications for at least 2 weeks prior to inclusion in the study. The inclusion criteria included age $\geqslant 60$ years of age, Englishspeaking, and hearing and visual ability sufficient to complete the full neuropsychological battery.

\section{Study Design}

Volunteers were screened for this cross-sectional study with the SCID, given a neurological examination by a clinical geriatric psychiatrist, and administered the Mini-Mental State Examination (MMSE) (Folstein et al, 1975) and the Cumulative Illness Rating Scale, a commonly used measure of medical comorbidity among geriatric patients (Linn et al, 1968). None of the participants had a history or mental status suggestive of dementia or any other brain disorder. Volunteers who passed the initial screening process completed an EKG and a standard battery of laboratory tests, including complete and differential blood counts; liver, renal, and thyroid screening tests; and measurement of electrolyte levels. Administration of a comprehensive neuropsychological battery and neuroimaging was completed within 2 weeks of the initial screening for depressed patients and within 4 weeks for the controls.

\section{MRS Acquisition and Postprocessing}

${ }^{1} \mathrm{H}$ MR spectra were acquired in the left dorsolateral prefrontal white matter region using a $1.5 \mathrm{~T}$ GE MRI/MRS scanner (GE Medical Systems, Waukesha, WI, USA), with a body coil for 'transmission' and a 3 in surface coil for 'reception'. The 3 in coil was placed directly on the forehead of the subject and a $3 \times 3 \times 3 \mathrm{~cm}^{3}$ voxel was positioned to the left side of the forehead, just above the eye to be closer to the left frontal white matter region. The 2D L-COSY sequence consisted of three slice-selective $\mathrm{rf}$ pulses $\left(90^{\circ}\right.$, $180^{\circ}$, and $90^{\circ}$ ) for the volume localization and the coherence transfer necessary for 2D-correlated spectroscopy (Thomas et al, 2003, 2001). A CHESS sequence was used for global water suppression prior to volume localization. 2D L-COSY spectra were recorded using the following parameters: $\mathrm{TE}=30 \mathrm{~ms}, \mathrm{TR}=2 \mathrm{~s}$, and the total number of scans of 800 (100 $\Delta t_{1}$ increments and 8 number of excitations per $\Delta t_{1}$ ), corresponding to a total duration of approximately $27 \mathrm{~min}$, respectively, for each $2 \mathrm{D}$ scan. The $2 \mathrm{D}$ raw matrix consisted of 1024 complex points along the first dimension and 100 points along the second dimension. The matrices were zero filled to $2048 \times 256$, and processed using a Felix-2000 package (Accelrys, San Diego, CA, USA). The volumes under the 2D diagonal and crosspeaks were calculated using manual peak picking on contours. The area of integration for each peak was kept constant in all the measurements as reported recently (Binesh et al, 2002). The ratio of each metabolite peak volume was calculated with respect to the diagonal peak of $\mathrm{Cr}\left(\mathrm{Cr} \_\mathrm{d}\right)$. Only the analysis of the four metabolites of $\mathrm{mI}, \mathrm{Pe}, \mathrm{PCh}$, and $\mathrm{Ch}$, which are the most likely to be associated with depression, and cognition are reported in this work (Figure 1).

We tested the reproducibility of 2D L-COSY spectra using phantom solutions and also, in a different location of adult human volunteers, the anterior cingulate gray matter (Binesh et al, 2002). In a total of 10 healthy volunteers, the following coefficients of variation of the ratios with respect to the diagonal peak of $\mathrm{Cr}$ were calculated: (a) $\mathrm{Ch}$ : 6.1\%; (b) mI: $15 \%$; (c) PCh: $26.1 \%$; and (d) Pe: $21.3 \%$. The coefficients of variance of the absolute $2 \mathrm{D}$ diagonal peak volumes of $\mathrm{Cr}$ and $\mathrm{Ch}$ were 19 and 20\%, respectively.

The volumes under the diagonal peaks of creatine $(\mathrm{Cr})$ and $\mathrm{Ch}$ were calculated at $\left(F_{2}=F_{1}=3.0 \mathrm{ppm}\right)$ and $\left(F_{2}=F_{1}=3.2 \mathrm{ppm}\right) \quad\left(\right.$ denoted as $\mathrm{Cr} \_\mathrm{d}$ and $\mathrm{Ch} \_\mathrm{d}$, respectively). Four $2 \mathrm{D}$ crosspeaks were selected at the following locations: $\mathrm{mI}\left(F_{2}=3.5 \mathrm{ppm}, \quad F_{1}=3.1 \mathrm{ppm}\right)$, Ch $\quad\left(F_{2}=4.0 \mathrm{ppm}, \quad F_{1}=3.5 \mathrm{ppm}\right), \quad \mathrm{Pe} \quad\left(F_{2}=4.0 \mathrm{ppm}\right.$, $\left.F_{1}=3.15 \mathrm{ppm}\right)$, and $\mathrm{PCh}\left(F_{2}=4.3 \mathrm{ppm}, F_{1}=3.7 \mathrm{ppm}\right)$. The peak volumes of crosspeaks above the diagonal were discarded due to the asymmetry effect (Banaker et al, 2002). The $\mathrm{mI}$ crosspeaks were identified at two locations, the first at $F_{2}=3.5 \mathrm{ppm}$ and $F_{1}=3.1 \mathrm{ppm}$ solely due to mI and the second at $F_{2}=4.0 \mathrm{ppm}$ and $F_{1}=3.5 \mathrm{ppm}$ overlapping with free $\mathrm{Ch}$, so the former was used for this analysis. The PCh peak overlaps with glycerylphosphocholine, and the Pe peak overlaps with glycerophosphethanolamine. The assignments of these peaks were guided by the 2D L-COSY spectra of individual phantom solutions of several metabolites (Thomas et al, 2001) and a previous report on the 1D MRS chemical shifts (Govindaraju et al, 2000). 


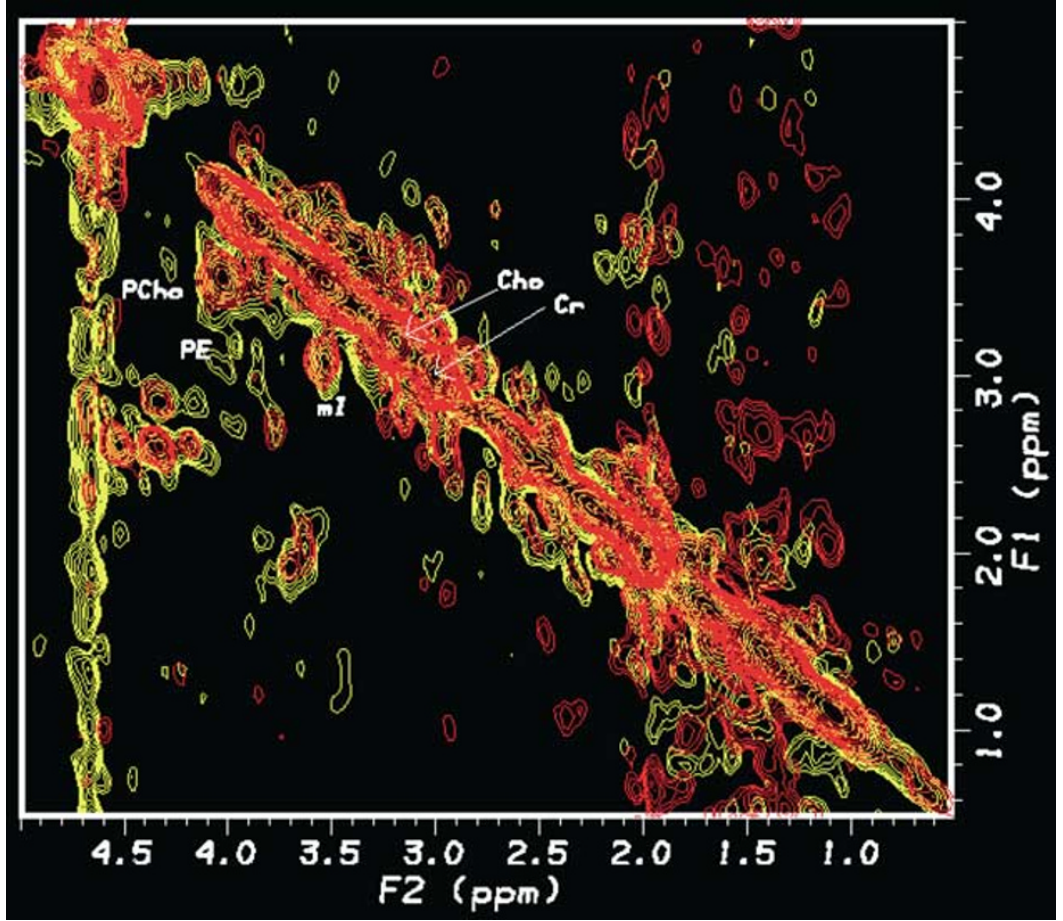

Figure I The spectra of a depressed patient (red) superimposed on a healthy control (yellow). (TE $=30 \mathrm{~ms} ; \mathrm{TR}=2 \mathrm{~s} ; \quad 100 \mathrm{rows}$; eight averages). Intergroup t-tests showed no significant differences in metabolite levels.

\section{MRI Methods}

The volumes of intracranial gray matter, white matter, and CSF volumes in the MRS voxel were calculated from $T_{1}$ weighted, three-dimensional (3D) volumetric spoiled gradient recalled echo (SPGR) images acquired using the following parameters: $1.6-\mathrm{mm}$ slice thickness, $22 \times 16.5 \mathrm{~cm}^{2}$ field of view, 124 contiguous partitions, 192 views, and $45^{\circ}$ flip angle $(\mathrm{TE}=5 \mathrm{~ms}, \mathrm{TR}=42 \mathrm{~ms}$ ). A conventional quadrature head coil was used for the volumetric MRI. The spectroscopy voxels $\left(3 \times 3 \times 3 \mathrm{~cm}^{3}\right)$ were localized on a $\mathrm{T}_{1}$ weighted axial MRI recorded using a 3 in surface 'receive' coil acquired at the same scanning session as the 3D SPGR data. Segmentation of the 3D MRI data was accomplished with a minimum distance classifier algorithm (Kollokian, 1996), which has been previously described (Kumar et al, 2002).

\section{Neuropsychological Battery}

The neuropsychological tests were selected to characterize six neuropsychological domains that have been associated with the left lateral cortex by lesion analysis and neuroimaging: verbal learning, verbal recall, verbal recognition, verbal executive function, hypothesis generation, and processing speed. Loading of test variables on domain scales was based on an a priori assessment of content validity, which has been used by others (Bilder et al, 2000; Cannon et al, 1994) and which has been demonstrated in a principle component analysis with a larger sample (Blanchard and Neale, 1994; Elderkin-Thompson et al, 2003a).

The domain scales and contributing tests were as follows: verbal learning: California Verbal Learning Test (CVLT)
(Delis et al, 1987), trials $1-5$ inclusive, trial 1, and trial 5; verbal recall: CVLT short-delayed free recall and longdelayed free recall; verbal recognition: CVLT recognition, Recognition Memory Test for Words (RMT) (Warrington, 1984); verbal executive function: Stroop Interference Trial (Stroop, 1935), Trailmaking Part B (Lezak, 1995); hypothesis generation: Wisconsin Card Sort Test (WCST) (Heaton et al, 1993) conceptual responses and categories achieved; and processing speed: WAIS-III Digit Symbol (Wechsler, 1997), Stroop 1 (Color Naming) and Stroop 2 (Word ReadingKaplan version);(Mitrushina et al, 1999), and Trailmaking Part A (Lezak, 1995).

\section{Data Analysis}

Sample characteristics were examined with Student's $t$-tests for continuous variables and $\chi^{2}$ for nominal variables. Scatterplots of cognitive test scores were examined for outliers $>2$ SD before scores were converted to $z$ scores using the mean and standard deviation of the healthy comparison group. Composite scale scores for each domain were computed by averaging $z$ scores of contributing variables per the a prior protocol. All scales were computed so that higher scores indicated better performance. The spectroscopy estimates of the absolute contour volumes of $\mathrm{mI}, \mathrm{Ch}, \mathrm{Pe}, \mathrm{PCh}$, and $\mathrm{Cr}$ were used to determine the ratios. Even though $\mathrm{Cr}$ tends to increase over the lifespan (Chang et al, 1996; Pfefferbaum et al, 1999), within a limited age span as represented in this sample, the $C R$ is likely to be sufficiently stable to allow for comparisons between the diagnostic groups. $T$-tests were computed to confirm that $\mathrm{Cr}$ levels were comparable between groups $($ controls $=670.14 \quad( \pm 131.04 \mathrm{SD})$ and patients $=689.36$ 
Table I Demographic and Clinical Information of Patients and Controls

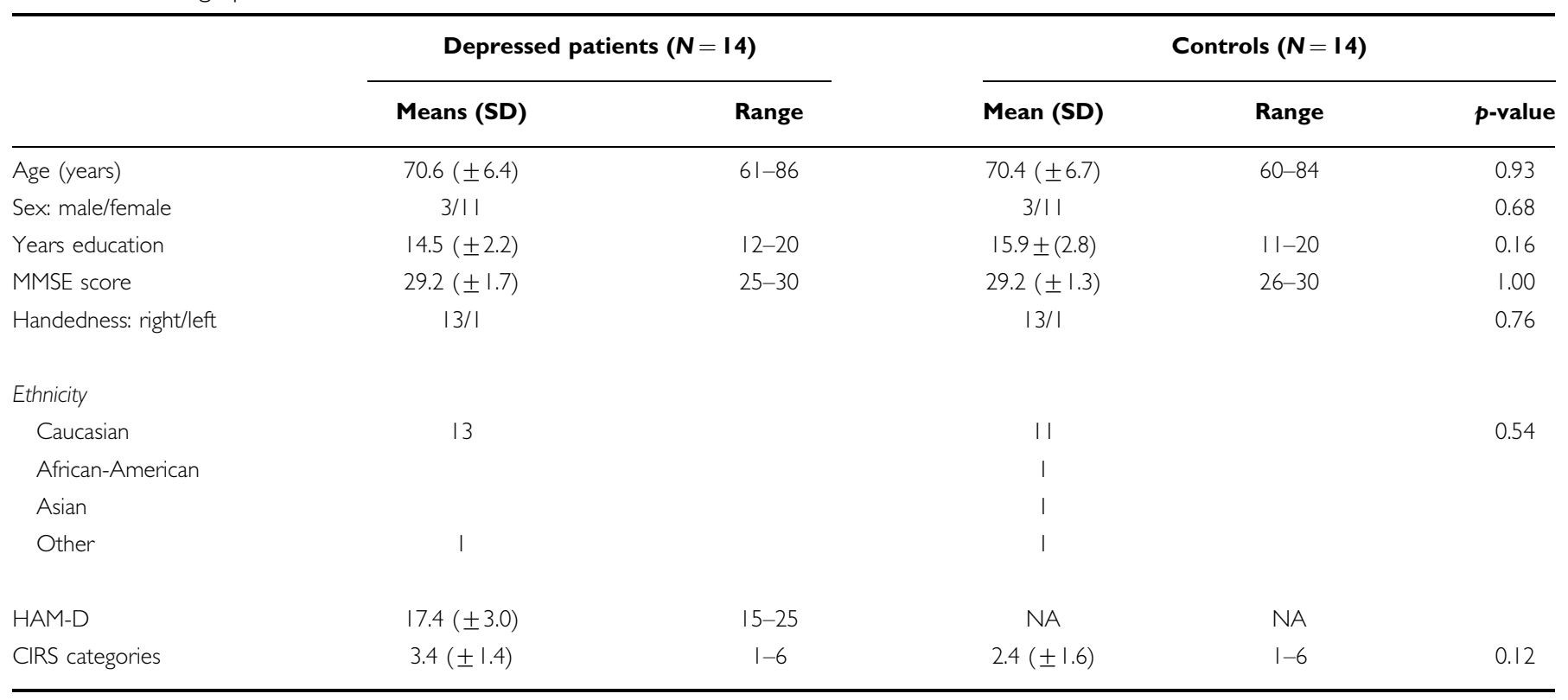

NA $=$ not applicable.

( \pm 105.27 SD), $p=0.67)$ and between young (60-69 years, $N=13)$ and old (70-90 years, $N=15)$ subjects $(t(1.299)=0.21$, df 26$)$ before ratios were computed using $\mathrm{Cr}$ as the denominator.

Multiple regression analyses were used to examine how efficiently the metabolites predicted cognitive function in the depressed and control groups, and to assess whether the four-metabolite model differed across groups. In the separate univariate regression analyses, the dependent variables were the composite neuropsychological scores, and the independent variables were the four metabolites, diagnosis (a dummy variable coded $1=$ depressed and $0=$ control), and the interaction terms (each metabolite $\times$ diagnosis). Education was entered as a covariate. The interaction terms showed the differences between the two diagnostic groups in the slope of each of the four metabolites for each dependent variable. Planned contrasts were performed that tested the overall predictive models within each group, and tested the significance of the overall group differences for the model as a whole (both of these tests have numerator $\mathrm{df}=4$ ) (Table 1$)$.

\section{RESULTS}

The standardized regression coefficients for each diagnostic group and the difference scores are displayed in Table 2. Overall, the four metabolites accounted for 34 to $55 \%$ of the unexplained variance in the composite cognition scales. Among the healthy participants, the four-metabolite model successfully predicted Verbal Learning and Verbal Recognition scores, with Hypothesis Generation and Processing Speed scores showing a trend toward significance $(p=0.02$, 0.03 , 0.18, and 0.14, respectively). Among depressed patients, the model predicted scores on the Processing Speed scale $(p=0.04)$, but it did not predict any of the other domains. Difference analysis indicated that the metabolite models differed significantly between healthy and depressed groups in Verbal Learning and Processing Speed $(p=0.02$ and 0.03 , respectively).

In terms of the individual metabolites, the $\mathrm{Ch} / \mathrm{Cr}$ ratios of healthy controls were significant and positive predictors of Verbal Learning, Verbal Recall, Verbal Recognition and Hypothesis Generation scales $(p=0.02,0.04,0.02$, and 0.04 , respectively). $\mathrm{mI} / \mathrm{Cr}$ significantly predicted Verbal Learning $(p=0.01)$ and Verbal Recognition $(p<0.01)$ and had moderate but nonsignificant coefficients in the remaining two composite scores of Verbal Recall and Hypothesis Generation ( $p=0.19$ and 0.11 , respectively). In contrast, negative coefficients emerged between $\mathrm{PCh} / \mathrm{Cr}$ and the same four composite scales, with a significant coefficient for Verbal Learning $(p=0.05)$. In contrast, the depressed group showed no pattern of associations between the cognitive domains and the metabolites. Only one individual relationship was significant, the $\mathrm{mI} / \mathrm{Cr}$ association with Processing Speed.

The differences in regression coefficients (ie, the interaction terms) are computed by subtracting the coefficients of controls from those of patients in planned contrasts. Negative values indicate a greater positive slope for controls than for depressed patients. Thus, cognitive performance of controls improved to a greater degree as the volume of $\mathrm{Ch} /$ $\mathrm{Cr}$ and $\mathrm{mI} / \mathrm{Cr}$ increased than it did among depressed persons. The difference between the slopes reached significance for the $\mathrm{Ch} / \mathrm{Cr}$ and $\mathrm{mI} / \mathrm{Cr}$ volumes in Verbal Learning $(p=0.03$ and 0.01 , respectively). The slopes showed a trend for increasing $\mathrm{Ch} / \mathrm{Cr}$ and better performance in healthy volunteers in Verbal Recall $(p=0.08)$ and for $\mathrm{mI} / \mathrm{Cr}$ in Verbal Recognition $(p=0.06)$ and Hypothesis Generation $(p=0.10)$. Although the differences between the $\mathrm{PCh} / \mathrm{Cr}$ slopes for depressed and healthy groups in Learning, Recall, Recognition, and Hypothesis Generation 
were modest and nonsignificant, they were all positive. Thus, the slopes for controls were more negative than were the slopes for depressed patients in the PCh and cognition associations, indicating a different association among controls than among patients. The results must be interpreted with caution due to the small sample size, but the results that form a pattern are considered more likely to represent real than chance findings.

\section{CONCLUSION}

To our knowledge this is the first study to examine the relationship between cognition and the individual metabolites of $\mathrm{Ch} / \mathrm{Cr}, \mathrm{Pe} / \mathrm{Cr}, \mathrm{PCh} / \mathrm{Cr}$, and $\mathrm{mI} / \mathrm{Cr}$ among depressed and healthy elderly volunteers. Healthy elderly subjects and patients with MDD showed different relational patterns between the metabolites measured in the left dorsolateral white matter and cognitive domains. Among healthy elderly controls, increased $\mathrm{Ch} / \mathrm{Cr}$ and $\mathrm{mI} / \mathrm{Cr}$ and decreased $\mathrm{PCh} / \mathrm{Cr}$ were associated with better performance in verbal learning, recall, recognition, and hypothesis generation. In contrast, depressed patients showed an inconsistent pattern of relationships between metabolites and cognition. Second, there was a significant difference between patients and controls in the overall pattern of relationships between the four metabolites and cognitive performance in verbal learning and speed of processing. Third, there were no significant associations between executive function and the four metabolites or the overall model.

The difference scores between the healthy and depressed elders indicated that depressed patients did not experience an increase in cognitive function with increasing $\mathrm{Ch} / \mathrm{Cr}$ and $\mathrm{mI} / \mathrm{Cr}$ levels as was seen among healthy participants. Although $\mathrm{PCh} / \mathrm{Cr}$ correlated negatively with cognitive function in the four domains of verbal learning, recall, recognition, and hypothesis generation for both healthy and depressed participants, the association was weaker among depressed persons than among healthy participants. The lack of benefit derived from increased $\mathrm{Ch} / \mathrm{Cr}$ and $\mathrm{mI} / \mathrm{Cr}$ among depressed patients suggests a loss of integrated biochemical concentrations that appear necessary for efficient cognitive function.

Ch and inositol are common precursors of phosphoglycerides, one of the three major kinds of membrane lipids (Styor, 1988). By providing in vivo estimates of $\mathrm{Ch}$ concentration, MR spectroscopy is thought to provide information on membrane turnover (Gadian, 1995), the degree of myelination (Hida et al, 1992), and cell density (Miller et al, 1996). The Ch concentration is reported to vary with the production and degradation of the Ch-containing phospholipids, which are abundant in cell membrane and in myelin (Miller et al, 1996; Alberts et al, 2002; Styor, 1988). An abnormality in membrane structure or myelination could precipitate decreased synaptic strength and efficiency, manifesting in cognitive deficits.

Changes in phospholipid turnover and gliosis are the most plausible explanations for the abnormal relationship between cognition and $\mathrm{mI} / \mathrm{Cr}$ observed among depressed patients in this study (Robertson et al, 2001). mI is known to be abundant in glia although it is also involved in several other important cellular processes in the brain such as 
cellular osmoregulation and secondary messenger trafficking (Brand et al, 1993; Chang et al, 1996; Robertson et al, 2001; Ross et al, 1996). In mild HIV brain injury, before clinical and cognitive signs of the disease are apparent but after gliosis has begun to increase, cognitive tasks require increased activated brain volume for completion, and the increase is independent of task complexity (Ernst et al, 2002). Thus, more activation (or mental effort) is required to maintain the same level of response performance. Post-mortem findings in patients with mood disorders demonstrated abnormalities in both neuronal and glial compartments in patients with mood disorders (Rajkowska, 2000). Abnormalities in glial function could alter the levels of neurochemicals in critical brain regions, thereby impacting on neuronal circuitry and the cognitive function dependent on that circuitry.

In conclusion, among depressed patients the brain metabolites of $\mathrm{Ch} / \mathrm{Cr}, \mathrm{Pe} / \mathrm{Cr}, \mathrm{PCh} / \mathrm{Cr}$, and $\mathrm{mI} / \mathrm{Cr}$ are not associated with cognition in the same manner as seen among healthy elderly persons. While healthy elders use higher levels of $\mathrm{Ch} / \mathrm{Cr}, \mathrm{mI} / \mathrm{Cr}$, and $\mathrm{Pe} / \mathrm{Cr}$ and a lower level of $\mathrm{PCh} / \mathrm{Cr}$ advantageously, depressed patients demonstrate no clear patter of associations with the metabolites. Abnormalities in cellular membrane structure and/or gliosis could lead to alterations in frontostriatal circuitry that modulate cognitive processes.

\section{ACKNOWLEDGEMENTS}

This research was supported by NIH Grants RO1 MH 63764, RO1 MH 61567, and KO2 MH 02043 (A Kumar, PI).

\section{REFERENCES}

Alberts B, Johnson A, Lewis J, Raff M, Roberts K, Walter P (2002). Mol Biol Cell. Garland Science: New York. pp 583-657.

Banaker S, Venkatraman T, Yue K, Binesh N, Thomas MA (2002). Asymmetry of localized two-dimensional shift correlated MR spectroscopy. Presented at the International Conference on Mathematics and Engineering Techniques in Medicine and Biological Sciences, June 24-27, 2002, pp 500-504.

Bilder RM, Goldman RS, Robinson C, Reiter G, Bell L, Bates JA et al (2000). Neuropsychology of first-episode schizophrenia: Initial characterization and clinical correlates. Am J Psychiatry 157: 549-559.

Binesh N, Yue K, Fairbanks L, Thomas MA (2002). Reproducibility of localized correlated 2D MR spectroscopy. Magn Reson Med 48: 942-948.

Blanchard JJ, Neale JM (1994). The neuropsychological signature of schizophrenia: generalized or differential deficit? $A m J$ Psychiatry 151: 40-48.

Brand A, Richter-Landsberg C, Leibfritz D (1993). Multinuclear NMR studies on the energy metabolism of glial and neuronal cells. Dev Neurosci 15: 289-298.

Cannon TD, Zorrilla LE, Shtasel D, Gur RC, Marco EH, Moberg PJ (1994). Neuropsychological functioning in siblings discordant for schizophrenia and healthy volunteers. Arch Gen Psychiatry 51: 651-661.

Catani M, Mecocci P, Tarducci R, Howard R, Pelliccioli GP, Mariani E et al (2002). Proton magnetic resonance spectroscopy reveals similar white matter biochemical changes in patients with chronic hypertension and early Alzheimer's disease. $\mathrm{J} \mathrm{Am}$ Geriatr Soc 50: 1707-1710.
Catani M, Piccirilli M, Cherubini A, Tarducci R, Sciarma T, Gobbi $\mathrm{G}$ et al (2003). Axonal injury within language network in primary progressive aphasia. Ann Neurol 53: 242-247.

Chang L, Ernst T, Poland RE, Jenden DJ (1996). In vivo proton magnetic resonance spectroscopy of the normal aging human brain. Life Sci 58: 2049-2056.

Charles HC, Lazeyras F, Krishnan KRR, Boyko OB, Payne M, Moore D (1994). Brain choline in depression-in-vivo detection of potential pharmacodynamic effects of antidepressant therapy using hydrogen localized spectroscopy. Prog Neuropsychopharmacol Biol Psychiatry 18: 1121-1127.

Delis DC, Kramer JH, Kaplan E, Ober BA (1987). California Verbal Learning Test: Adult Version. The Psychological Corporation: San Antonio.

Drevets WC, Raichle ME (1992). Neuroanatomical circuits in depression: implications for treatment mechanisms. Psychopharmacol Bull 28: 261-274.

Elderkin-Thompson V, Kumar A, Bilker WB, Dunkin JJ, Mintz J, Moberg PJ et al (2003a). Neuropsychological deficits among patients with late-onset minor and major depression. Arch Clin Neuropsychol 615: 1-21.

Ernst T, Chang L, Jovicich J, Ames N, Arnold S (2002). Abnormal brain activation on functional MRI in cognitively asymptomatic HIV patients. Neurology 59: 1343-1349.

Folstein MF, Folstein SE, McHugh PR (1975). 'Mini Mental State': a practical method for grading the cognitive state of patients for the clinician. J Psychiatr Res 12: 189-198.

Fuster J (2000). Executive frontal functions. Exp Brain Res 133: 6670.

Fuster J (2001). The prefrontal cortex - an update: time is of the essence. Neuron 30: 319-333.

Gadian DG (1995). N-acetylaspartate and epilepsy. Magn Reson Imaging 13: 1193-1195.

Goldman-Rakic PS (1995). Architecture of the prefrontal cortex and the central executive. In Grafman J, Boller F, Holyoak K (eds). Structure and Functions of the Human Prefrontal Cortex. New York Academy of Sciences: New York. pp 71-83.

Govindaraju V, Young K, Maudsley AA (2000). Proton NMR chemical shifts and coupling constants for brain metabolites. NMR Biomed 13: 129-153.

Hamakawa H, Kato T, Murashita J, Kato N (1998). Quantitative proton magnetic resonance spectroscopy of the basal ganglia in patients with affective disorders. Eur Arch Psychiatry Clin Neurosci 248: 53-58.

Hamilton MA (1960). A rating scale for depression. J Neurol Neurosurg Psychiatry 23: 56-62.

Heaton RK, Chelune GJ, Talley JL, Kay GG, Curtiss G (1993). Wisconsin Card Sorting Test Manual. Psychological Assessment Resources Inc.: Odessa, FL.

Hida K, Kwee IL, Nakada T (1992). In vivo H-1 and P-31 Nmrspectroscopy of the developing rat-brain. Magn Reson Med 23: $31-36$.

Huang W, Alexander GE, Daly EM, Shetty U, Krasuski JS, Rapoport SI et al (1999). High brain myo-Inositol levels in the predementia phase of Alzheimer's disease in adults with down's syndrome: a 1H MRS study. Am J Psychiatry 156: $1879-1886$.

Kantarci K, Jack Jr CR, Xu YC, Campeau NG, O'Brien PC, Smith GE et al (2000). Regional metabolic patterns in mild cognitive impairment and Alzheimer's disease: a $1 \mathrm{H}$ MRS study. Neurology 55: 210-217.

Kollokian V (1996). Performance Analysis of Automatic Techniques for Tissue Classification in Magnetic Resonance Images of the Human Brain (Master's thesis). Concordia University, Department of Computer Science: Montreal.

Kumar A, Cook IA (2002). White matter injury, neural connectivity and the pathophysiology of psychiatric disorders. Dev Neurosci 24: 255-261. 
Kumar A, Thomas A, Lavretsky H, Yue K, Huda A, Curran J et al (2002). Frontal white matter biochemical abnormalities in latelife major depression detected with proton magnetic resonance spectroscopy. Am J Psychiatry 159: 603-636.

Lezak MD (1995). Neuropsychological Assessment. Oxford University Press: New York.

Linn BJ, Linn BW, Gurel L (1968). Cumulative Illness Rating Scale. J Am Geriatr Soc 16: 622-626.

Lopez-Villegas D, Lenkinski RE, Frank I (1997). Biochemical changes in the frontal lobe of HIV-infected individuals detected by magnetic resonance spectroscopy. Proc Natl Acad Sci USA 94: 9854-9859.

Mesulam M-M (2000). Principles of Behavioral and Cognitive Neurology. Oxford University Press: New York.

Miller BL (1991). A review of chemical issues in $1 \mathrm{H}$ NMR spectroscopy: $N$-acetyl-L-aspartate, creatine and choline. $N M R$ Biomed 4: 47-52.

Miller BL, Chang L, Booth R, Ernst T, Cornford M, Nikas D et al (1996). In vivo $1 \mathrm{H}$ MRS choline: correlation with in vitro chemistry/histology. Life Sci 58: 1929-1935.

Mitrushina MN, Boone KB, D'Elia LF (1999). Handbook of Normative Data for Neuropsychological Assessment. Oxford University Press: New York.

Pfefferbaum A, Adalsteinsson E, Spielman D, Sullivan EV, Lim KO (1999). In vivo spectroscopic quantification of the $N$-acetyl moiety, creatine, and choline from large volumes of brain gray and white matter: effects of normal aging. Magn Reson Med 41: 276-284.

Price JL (2001). Networks within the orbital and medial prefrontal cortex. Neurocase 5: 231-241.

Rajkowska G (2000). Postmortem studies in mood disorders indicate altered numbers of neurons and glial cells. Biol Psychiatry 48: 766-777.

Renshaw PF, Lafer B, Babb SM, Fava M, Stoll AL, Christensen JD et al (1997). Basal ganglia choline levels in depression and response to fluoxetine treatment: an in vivo proton magnetic resonance spectroscopy study. Biol Psychiatry 41: 837-843.

Robertson NJ, Lewis RH, Cowan FM, Allisop JM, Counsell SJ, Edwards AD et al (2001). Early increases in brain myo-Inositol measured by proton magnetic resonance spectroscopy in term infants with neonatal encephalapathy. Pediatr Res 30: 692-700.

Ross BD, Danielsen ER, Bluml S (1996). Proton magnetic resonance spectroscopy: the new gold standard for diagnosis of clinical and subclinical hepatic encephalopathy? Dig Dis 14(Suppl 1): 30-39.

Shonk TK, Moats RA, Gifford P, Michaelis T, Mandigo JC, Izumi J et al (1995). Probable Alzheimer disease: diagnosis with proton MR spectroscopy. Radiology 195: 65-72.

Steingard RJ, Yurgelun-Todd DA, Hennen J, Moore JC, Moore CM, Vakili $\mathrm{K}$ et al (2000). Increased orbitofrontal cortex levels of choline in depressed adolescents as detected by in vivo proton magnetic resonance spectroscopy. Biol Psychiatry 48: 1053-1061.

Stroop JR (1935). Studies of interference in serial verbal reactions. J Exp Psychol 18: 643-662.

Styor L (1988). Introduction to biological membranes. In: Styor L (ed). Biochemistry. WH Freeman: New York. pp 283-312.

Thomas AJ, O'Brien JT, Davis S, Ballard C, Barber R, Kalaria RN et al (2002). Ischemic basis for deep white matter hyperintensities in major depression: a neuropathological study. Arch Gen Psychiatry 59: 785-792.

Thomas MA, Hattori N, Umeda M, Sawada T, Naruse S (2003). Evaluation of two-dimensional L-COSY and JPRESS using a $3 \mathrm{~T}$ MRI scanner; from phantoms to human brain in vivo. $\mathrm{Nucl}$ Magn Reson Biomed 16.

Thomas MA, Yue K, Binesh N, Davanzo P, Kumar A, Siegel B et al (2001). Localized two-dimensional shift correlated MR spectroscopy of human brain. Magn Reson Med 46: 58-67.

Warrington EK (1984). Recognition Memory Test. NFER-Nelson: Windsor, UK.

Wechsler D (1997). WAIS-III: Administration and Scoring Manual. The Psychological Corporation: San Antonio. 